\title{
Vitamin D and its role in psoriasis: An overview of the dermatologist and nutritionist
}

\author{
Luigi Barrea $^{1}$ - Maria Cristina Savanelli ${ }^{1}$ Carolina Di Somma ${ }^{2}$.

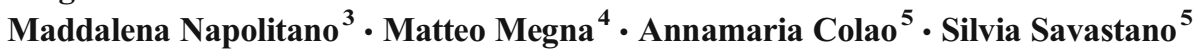

Published online: 7 February 2017

(C) The Author(s) 2017. This article is published with open access at Springerlink.com

\begin{abstract}
Psoriasis is a chronic immune-mediated inflammatory skin disease. Psoriasis lesions are characterized by hyperproliferation of epidermal keratinocytes associated with inflammatory cellular infiltrate in both dermis and epidermis. The epidermis is the natural source of vitamin D synthesis by sunlight action. Recently, a role for vitamin D in the pathogenesis of different skin diseases, including psoriasis, has been reported. Indeed, significant associations between low vitamin D status and psoriasis have been systematically observed. Due to its role in proliferation and maturation of keratinocytes, vitamin D has become an important local therapeutic option in the treatment of psoriasis. To date, the successful treatment based on adequate dietary intake of vitamin D or oral vitamin D supplementation in psoriasis represent an unmet clinical need and the evidence of its beneficial effects remains still controversial. This information is important either for Dermatologists and Nutritionists to increases the knowledge on the possible bi-directional relationships between low vitamin D status and psoriasis and on the potential
\end{abstract}

usefulness of vitamin D in psoriasis with the aim not only to reduce its clinical severity, but also for delineating the risk profile for co-morbidities cardiac risk factors that may result from psoriasis. In the current review, we analyzed the possible bi-directional links between psoriatic disease and vitamin D.

Keywords Environmental factors · Vitamin D · Psoriasis · Dermatologist $\cdot$ Nutritionist $\cdot$ Nutrition

\section{Introduction}

Psoriasis is a chronic immune-mediated inflammatory skin disease, with a prevalence of about $2 \%-3 \%$ in the general population [1]. The primary manifestation of psoriasis most commonly manifests on the skin, although inflammatory processes can occur also in other organs [1]. Indeed, nowadays psoriasis is considered a systemic pathology, including also other conditions, from psoriatic arthritis to obesity and meta-
Silvia Savastano

sisavast@unina.it

Luigi Barrea

luigi.barrea@unina.it

Maria Cristina Savanelli

cristysav@hotmail.com

Carolina Di Somma

cdisomma@unina.it

Maddalena Napolitano

maddy.napolitano@gmail.com

Matteo Megna

mat24@libero.it
Annamaria Colao

colao@unina.it

I.O.S. \& COLEMAN Srl, Acerra, 80011 Naples, Italy

2 IRCCS SDN, Napoli Via Gianturco 113, 80143 Naples, Italy

3 Dipartimento di Medicina e Scienze della Salute "Vincenzo Tiberio", Rheumatology Unit, University of Molise, Via Francesco De Sanctis 1, 86100 Campobasso, Italy

4 Dipartimento di Medicina Clinica e Chirurgia, Unit of Dermatology, Federico II University Medical School of Naples, Via Sergio Pansini 5, 80131 Naples, Italy

5 Dipartimento di Medicina Clinica e Chirurgia, Unit of Endocrinology, Federico II University Medical School of Naples, Via Sergio Pansini 5, 80131 Naples, Italy 
bolic disease (MetS), which increased cardiovascular risk in psoriatic patients [2-4]. Histologically, the dermatosis is characterized by hyperproliferation of keratinocytes, impaired epidermal barrier function at the sites of skin lesions, and skin infiltration by activated inflammatory cells [5]. The aetiology of psoriasis is not fully understood. Several factors contribute to its development, such as auto-immunological, genetic, hormonal and psychosomatic issues [6].

Vitamin D, also known as the sunshine vitamin, has long been known to be a hormone that regulates calciumphosphorous homeostasis and safeguards the integrity of the skeletal system [7]. The epidermis is the natural source of vitamin D synthesis by the action of ultraviolet light (UV) B of the sun or other UVB source [8]. On the other hand, evidence is accumulating that vitamin D might represent a key modulator of immune and inflammation mechanisms [9]. Recently, a role for vitamin $\mathrm{D}$ in the pathogenesis of different skin diseases, including psoriasis, has been reported [9-11]. However, the effectiveness of vitamin D supplementation as adjunctive treatment option in psoriatic patients still remains controversial [9-11]. In the current review, we analyzed the possible bi-directional links between vitamin $\mathrm{D}$ and psoriatic disease.

\section{The dermatologist's point of view}

Patients suffering from psoriasis present a broad range of clinical phenotypes. Psoriatic lesions are classified into plaque, guttate, pustular, and erythrodermic types according to clinical features, especially regarding lesions size and distribution [1]. Disease onset may occur at any age, including childhood, with two peak age ranges, 16 to 22 and 57 to 60 years $[2,3]$. Psoriasis lesions are characterized by hyper-proliferation with incomplete differentiation of epidermal keratinocytes and decreased keratinocyte apoptosis, associated with inflammatory cellular infiltrate in both dermis and epidermis [12]. Psoriasis Area and Severity Index (PASI) score is currently the preferred method for the assessment of the disease severity and extent [13].

\subsection{Effects of vitamin D on skin biology}

The role of vitamin D as main regulator of skin physiology is very complex (Table 1). The epidermis is composed of four layers: basal layer (stratum basale), spinous layer (stratum spinosum), stratum granulosum and stratum corneum. The stem cells within the basal layer, which contact the basement membrane, continually divide during the lifetime of the organism, providing a source of cells which progressively migrate upwards through the epidermis, differentiating and stratifying to form the barrier layer of the skin [11, 14]. The process of epidermal differentiation is complex,
Table 1 Vitamin D actions on skin

Vitamin D actions on skin biology and psoriasis pathogenesis

Regulation of keratinocytes proliferation, differentiation and apoptosis

Regulation of cutaneous immune system (inhibition of $\mathrm{T}$ cell proliferation, Tregs induction)

Down-regulation of pro-inflammatory cytokines

Stimulation of antimicrobial peptides expression

Regulation of barrier integrity and permeability

Vitamin D actions on skin biology and psoriasis pathogenesis

Tregs, Regulatory T cells

sequential, and tightly controlled [11]. The precursor of vitamin D, 7-dehydrocholesterol, is located in the membranes of keratonocytes of the basal and spinous layer of epidermis [10]. By the action of UVB (wavelength between 290 and $315 \mathrm{~nm}$ ), via a photochemical reaction, the B ring of 7-dehydrocholesterol is broken to form pre-vitamin D3 or cholecalciferol, which is subsequently converted first to 25-hydroxyvitamin D (25OHD) by the enzymes CYP27A1 and CYP2R1 and then to 1,25-hydroxyvitamin D $(1,25(\mathrm{OH}) \mathrm{D}$ or calcitriol) the active form of vitamin $\mathrm{D}$, by CYP27B1 [15]. Physiologically, the active form of vitamin $\mathrm{D}$ and its receptor regulate the differentiation and proliferation of keratinocytes, the balance of the cutaneous immune system and the process of apoptosis. The $1,25(\mathrm{OH}) \mathrm{D}$ has been shown to exert anti-proliferative effects on keratinocytes [16]. Numerous in vitro and in vivo studies have demonstrated dose-dependent effects of vitamin $\mathrm{D}$ on proliferation and differentiation of keratinocytes. Of interest, low concentration of vitamin D promotes keratinocyte proliferation in vitro, while at higher pharmacological doses a clear inhibitory effect became apparent $[14,17]$. Moreover, 1,25(OH)D and analogs reduce S100A7 levels, generally up-regulated in psoriatic skin, in the reconstituted human epidermis stimulated by IL-22 [18], in interleukin (IL)-17-stimulated keratinocytes and in skin of patients with psoriasis [19]. Indeed, 1,25(OH)D regulates the cell proliferation in the stratum basale and increases the synthesis of keratins ( $\mathrm{K} 1$ and $\mathrm{K} 10$ ), involucrin, transglutaminase, loricrin, and filaggrin, in the stratum spinosum $[11,14,15]$. Furthermore, vitamin D helps to regulate the synthesis of glycosylceramides needful for the barrier integrity and permeability in the stratum corneum $[11,14,17]$. These actions are due to the capacity of vitamin D to regulate intracellular calcium level, through induction of the calcium receptor, and the phospholipase $\mathrm{C}$ enzymes $[19,20]$. A decrease or deficiency in $1,25(\mathrm{OH}) \mathrm{D}$ or a loss-of-function of its receptor has been shown to disrupt the differentiation of the epidermis, with reduced levels of involucrin and loricrin and loss of keratohyalin granules, resulting in hyperproliferation of the basal layer $[11,21-23]$. 


\subsection{Vitamin D regulation of apoptosis in keratinocytes}

Calcitriol stimulates the synthesis of ceramide by inducing the neutral $\mathrm{Mg}^{2+}$-dependent sphingomyelinase (thereby increasing the conversion of sphingomyelin to ceramide) and in return, ceramide enhances the pro-differentiating effect of calcitriol on keratinocytes in a feedback loop [10, 24]. It has been demonstrated that physiological concentrations of calcitriol do not initiate apoptosis in cultured keratinocytes but, in contrast, pharmacological concentrations of calcitriol exert a pro-apoptotic effect on keratinocytes [25].

\subsection{Effects of vitamin D on the cutaneous immune system}

Psoriasis pathogenesis implicates the innate and adaptive segments of the immune system. In particular, it is centrally controlled by $\mathrm{T}$ cells, in which an important role is played by $\mathrm{T}$ helper (Th)1, Th17 and Th22, interplaying with numerous cell types via different cytokines, including tumour-necrosis factor- $\alpha$ (TNF- $\alpha$ ), IL-6 and IL-17 [26]. The activity of these cells is modulated by specific $T$ lymphocytes, named regulatory T cells (Treg) [9]. Regulatory T cells (Tregs) are able to inhibit the immunological response and to preserve the cutaneous immunological homeostasis, preventing autoimmune response against self-antigens [27].

There is an increasing interest on broad regulatory effects exerted by vitamin D on cells of the adaptive and innate immune system [28]. Indeed, vitamin D acts as a pluripotent immunomodulator that inhibits proliferation of $\mathrm{T}$ lymphocytes, induces generation of CD25+/CD4+ Tregs, a phenotype of $\mathrm{T}$ cells promoting tolerance and inhibiting immunity after stimulation with antigen. Moreover, vitamin D induces the expression of the C-C chemokine receptor type 10 on surface of $\mathrm{T}$ lymphocytes, a receptor involved in T cell-mediated skin inflammation, leading their migration from dermal blood vessels to epidermal kerotinocytes [29]. Finally, vitamin D helps to defend from opportunistic infections, by inducing autophagy in human macrophages, and to support the innate skin barrier, by stimulating endogenous antimicrobial peptides expression in resident epithelial cells of the skin [9]. Antimicrobial peptides, like cathelicidins and defensins, have not only properties against bacteria, fungi and viruses, but also other immune regulatory properties, including cytokine and chemokine release, antigen presentation, cell proliferation, increasing vascular permeability, angiogenesis and wound healing [30].

\subsection{Vitamin D and psoriasis linkage}

In psoriasis, vitamin $\mathrm{D}$ is involved in the maintenance of cutaneous barrier homeostasis. Several studies identified an association between polymorphisms of vitamin D receptor $(V D R)$ and psoriasis susceptibility [9]. Richetta et al., have found that the A-1012G promoter polymorphism of the VDR gene is associated with psoriasis risk through a lower expression of $V D R$ mRNA, favoring conditions that may alter cutaneous barrier and the development of psoriatic lesions [31]. In addition, in psoriatic skin a decreased expression of $V D R$ and reduced tight-junction proteins is associated [32]. Tight junctions are fundamental to regulate adhesion and permeability of keratinocytes, and to polarize cutaneous cell differentiation, to regulate extracellular calcium gradient, interacting with nuclear and cytoplasmic proteins and influencing the regulation of specific genes involved in keratinocytes differentiation and proliferation [32, 33]. Different studies have focused on the possible role of low vitamin D status in the pathogenesis of psoriasis [34-36].

Indeed, several studies reported that vitamin D is a key modulator of inflammation function [37, 38]. The active metabolite of vitamin D exert an anti-inflammatory effect on the inflammatory profile of human monocytes/macrophage [39-42], down-regulating the expression and production of several pro-inflammatory cytokines including TNF- $\alpha$, IL$1 \beta$, IL-6, and IL-8 [43]. Moreover, dendritic cells differentiation, maturation, chemotaxis and antigen presentation seem to be dampened, and hydrogen peroxide secretion in human monocytes is also activated by $1,25(\mathrm{OH}) \mathrm{D}$ resulting in an increased oxidative burst potential $[9,44]$. These antiinflammatory effects support a role a low vitamin D status in the pathogenesis of psoriasis. Recent studies have shown that $1,25(\mathrm{OH}) \mathrm{D}$ values are significantly lower in psoriatic patients than in control subjects, even after adjusting for confounding factors in a multivariate analysis [11, 35]. In another study, vitamin D levels were lower in women with psoriasis in comparison with men, a difference not observed among controls [45]. Therefore, low levels of vitamin D are negatively associated with markers of inflammatory activation (C-reactive protein, CRP) and obesity [35]. Moreover, other studies showed that serum vitamin $\mathrm{D}$ levels were also reduced in patients with psoriatic arthritis and being inversely linked to disease activity [46, 47].

\subsection{Topical vitamin $D$ in psoriasis treatment}

The beneficial effects of vitamin D induced by exposure to sunlight in the treatment of psoriasis have been known for decades. The effectiveness on psoriasis of vitamin D and its derivatives (calcitriol, calcipotriol, tacalcitol, hexafluoro-1,25(OH)D and maxacalcitol) have been known since 1985, being confirmed in numerous trials $[45,48]$. The therapy with vitamin $\mathrm{D}$, is one of the most popularly prescribed topical medications for this disease as the first-line, singly or in combination with topical corticosteroids, and numerous studies documented the efficacy and safety of using topical calcipotriol in the treatment of cases of localized plaque 
psoriasis [49-54]. Vitamin D analogs are particularly helpful for hard-to-treat areas such as the face or inguinal regions that are sensitive to steroid-induced atrophy [55]. Vitamin D analogs do not exhibit tachyphylaxis, as seen with corticosteroids, and topical treatment can be continued indefinitely without serious adverse side effects $[9,55]$. Additionally, they are effective in the treatment of psoriatic skin lesions in children and elderly population [56-58]. A recent meta-analysis on the effectiveness of topical vitamin D therapies evidenced not only comparable efficacies to corticosteroids when used as monotherapy, but also superior effects when vitamin $\mathrm{D}$ used in combination with a potent topical steroid. According to these results, as topical vitamin D derivatives demonstrated a favorable safety profile, with "steroid-sparing" effects, and should be considered an indispensable component of the current physician's arsenal in the treatment of psoriasis [11].

The therapeutic effects of topical vitamin D occur via a $V D R$ mediated genomic mechanism resulting in inhibition of keratinocyte proliferation and mediated nongenomic mechanisms inducing keratinocyte differentiation by increasing intracellular calcium levels [59]. The anti-inflammatory effects may also result from inhibition of production of IL-2, IL-6, and interferon-gamma $($ IFN- $\gamma)$. Further, topical calcipotriol inhibits human beta defensin and proinflammatory cytokines which are found in increased levels in psoriatic lesions [60]. Allelic variations in individual VDR genes may determine a different response to treatment: the isoform A of $V D R$ is associated with a greater therapeutic response in psoriatic patients [61].

\section{The nutritionist's point of view}

Severe psoriasis has been associated with nutritional deficiencies because of an accelerated loss of nutrients, in particular of vitamin $\mathrm{D}$, from the hyperproliferation and desquamation of the epidermal layer of skin [62-64]. Vitamin D supplementation is of particular interest to Nutritionists for two important reasons. First, besides its topical use, oral vitamin D supplementation represents an important adjunctive treatment option for psoriatic patients [9]; second, vitamin D supplementation might be very important for the prevention of psoriasis-related comorbidity [65], hypertension [66] and metabolic syndrome [67].

\subsection{Food and vitamin D}

There are two ways to meet vitamin D requirements in mammals: via nutrition and via synthesis in skin by from the sun or other UVB source [8]. Several recommendations were published regarding the dietary intake of vitamin D [68-70]. In particular, these recommendations they refer to dietary reference intakes for calcium and vitamin $\mathrm{D}$ updated by the Institute of Medicine (IOM) in 2010 [71]. To date, as the evidence for extra-skelatal effects of vitamin $\mathrm{D}$ are inconsistent and insufficient, the intake recommendations were based on beneficial effects of vitamin D only on skeletal health. The Recommended Dietary Allowances (RDAs) covering requirements of $\geq 97.5 \%$ of the population are shown in Table 2 . Other organizations recommended different RDAs: the Endocrine Society suggested that adults aged 19-50 years require at least 600 international unit (IU) of vitamin D daily to maintain bone and muscular function [72]. However, the task force further annotated that 1500-2000 IU per day are necessary to consistently raise the serum level of $25(\mathrm{OH}) \mathrm{D}$ above $30 \mathrm{ng} / \mathrm{mL}$. Finally, for older adults aged 60 and above, the International Osteoporosis Foundation (IOF) recommended a RDA of $800-1000$ IU in order to reach a serum 25(OH)D level of $30 \mathrm{ng} / \mathrm{mL}$ [73].

The diet is an important determinant of vitamin D status [71, 74]. Some studies have calculated that the amount of vitamin $\mathrm{D}$ intake that would ensure that the majority of the population $(97.5 \%)$ maintains plasma $25(\mathrm{OH}) \mathrm{D}$ concentrations $>25 \mathrm{nmol} / 1$ throughout the year is $8.7 \mathrm{mg} / \mathrm{d}$ [75]. Only few foods contain naturally vitamin $\mathrm{D}$, and these foodstuffs are mainly of animal origin. The vitamin D status is the sum from the combination of synthesis in the skin after sun exposure and intake of the two main dietary forms of vitamin D: ergocalciferol (vitamin D2) and cholecalciferol (vitamin D3) [76]. The first is produced by plants, although fruits and vegetables in the human diet contain only minimal amounts of this nutrient, despite significant amounts of vitamin D2 are

Table 2 Vitamin D dietary reference intakes by life stage

\begin{tabular}{llll}
\hline Life-stage group & $\begin{array}{l}\text { RDA (intake that } \\
\text { covers needs } \\
\text { of } \geq 97.5 \% \text { of } \\
\text { population) }\end{array}$ & $\begin{array}{l}\text { Serum 25OHD level } \\
\text { (corresponding to } \\
\text { the RDA)* }\end{array}$ & \\
\cline { 2 - 3 } & IU/d & $\mathrm{mcg} / \mathrm{d}$ & $\mathrm{ng} / \mathrm{ml}$ \\
\hline Infants (0-12 months) & $400^{* *}$ & $10^{* *}$ & 20 \\
1-70 yr & 600 & 15 & 20 \\
$+70 \mathrm{yr}$ & 800 & 20 & 20 \\
Pregnant & 600 & 15 & 20 \\
Lactating & 600 & 15 & 20 \\
\hline
\end{tabular}

The Recommended Dietary Allowances (RDAs) covering requirements by life stage

$R D A$, Recommended Dietary Allowance; IU, International Unit

*Measures of serum $25(\mathrm{OH}) \mathrm{D}$ levels corresponding to the RDA and covering the requirements of at least $97.5 \%$ of the population

$* *$ Reflects adequate intake reference value rather than RDA. RDAs have not been established for infants 
available through dietary supplements. The mushrooms provide variable amounts of vitamin D2, and if exposed to ultraviolet light under controlled conditions, the mushrooms can improve their content of vitamin D2 [77, 78]. The vitamin D3 instead, is naturally found in some animal foods, particularly in fatty fish, including salmon, herring, and mackerel, and in fish oils [79]. The fish (especially fatty fish and fish liver) have the highest natural content of vitamin D [80] Also egg yolk has a high vitamin D3 content [80], which strongly correlates with the content of vitamin D3 of the hen's feed [77]. Depending on the hen's diet [81] and UVB exposure [82], the vitamin $\mathrm{D} 3$ and $25(\mathrm{OH}) \mathrm{D} 3$ were transferred from the hen to the egg yolk. Regarding of meat products, the content of vitamin $\mathrm{D}$ depends on the contents of vitamin $\mathrm{D}$ in the fodder, the fat content of the meat product, and latitude where the animals have grazed [83]. Finally, the vitamin D3 is also available through dietary supplements, and is the form present in vitamin D-fortified foods such as milk, orange juice, and cereals. The fortification of food with vitamin $\mathrm{D}$ has been considered to be the most promising strategy with the broadest reach and impact [84-86]. In fact, in countries where this strategy was adopted proved to have a significant influence on the daily vitamin $\mathrm{D}$ intake in the average adult [87]. The food sources of vitamin D are listed in Table 3 [88].

\subsection{Bioavailability and influence of processing and cooking}

The vitamin $\mathrm{D}$, like other fat-soluble vitamins (A, E, K), is absorbed incorporated in mixed micelles from the intestine into the enterocytes by non-saturable passive diffusion.

Table 3 Food sources of vitamin D[88]

\begin{tabular}{lll}
\hline Food & Amount & IUs per serving** \\
\hline Cod liver oil & 1 tablespoon & 1360 \\
Swordfish, cooked & $3 \mathrm{oz}$ & 566 \\
Salmon (sockeye), cooked & $3 \mathrm{oz}$ & 477 \\
Tuna fish, canned in water, drained & $3 \mathrm{oz}$ & 154 \\
Orange juice fortified with vitamin D & $1 \mathrm{cup}$ & 137 \\
$\quad$ (check product labels, as amount & & \\
$\quad$ of added vitamin D varies) & & \\
Milk, nonfat, reduced fat, and whole, & $1 \mathrm{cup}$ & $115-124$ \\
$\quad$ vitamin D-fortified & $2 \mathrm{sardines}$ & 46 \\
Sardines, canned in oil, drained & $3 \mathrm{oz}$ & 42 \\
Liver, beef, cooked & 1 large & 41 \\
Egg (vitamin D is found in yolk) & $1 \mathrm{oz}$ & 6 \\
Cheese, Swiss & &
\end{tabular}

The food sources of vitamin D

$* 1 \mathrm{oz}=28,3495 \mathrm{~g}$

**IU = International Units
Subsequently, the vitamin D is transported in the chylomicrons via lymph to the circulation [89]. The more polar metabolite 25(OH)D is absorbed better and faster than vitamin $\mathrm{D}$ because it is also taken up directly from the proximal jejunum into the portal vein [79]. There are few data on its availability from natural sources. The absorption of vitamin D from supplements may differ depending on the used vehicle substance, such as oils, powders, ethanol [90]. For example, it has been reported that the bioavailability of vitamin D from fortified hard cheese is equivalent to supplements [91] and that vitamin $\mathrm{D}$ bioavailability is not influenced by the fat content of the fortified milk [92].

The cooking does not much influence the vitamin D content of animal foods. Mattila et al. [93] found that, in eggs boiled for $10 \mathrm{~min}$, the vitamin D3 concentration was $1-6 \%$ lower and $25(\mathrm{OH})-\mathrm{D}-3$ content was $6-11 \%$ lower compared with raw eggs. In addition, also in fish, the cooking effect was moderate: baking various kinds of fish (e.g., perch, rainbow trout, Baltic herring) in the oven at $172{ }^{\circ} \mathrm{C}$ or $200{ }^{\circ} \mathrm{C}$ for 20 min induced a vitamin D3 loss of $<10 \%$, calculated on a dry matter basis [93]. The stability of vitamin D3 and 25(OH)D and vitamin D2 in foodstuffs during cooking has been shown to vary widely with heating process and foodstuffs, with reported retentions in eggs, margarine and bread after boiling, frying and baking of between $40 \%$ and $88 \%$ [94].

\subsection{The nutritionist and vitamin D supplementations}

Supplements are the most important determinant of variation in vitamin D intake [85, 86, 95] A number of studies showed that the daily intake of vitamin $\mathrm{D}$ was higher in adults using vitamin D supplements than in those without vitamin D supplementations (348 IU vs 84 IU of vitamin D) [86]. Most nutritionists recommend the use of vitamin D3 to treat and prevent vitamin D deficiency, because several studies indicating a higher efficacy for vitamin D3 in raising serum $25(\mathrm{OH}) \mathrm{D}$ concentrations when compared to vitamin D2 [96]. Although a significant inter-individual variation exists, due to different variables including body weight, sunlight exposure and calcium intake, it has been calculated that supplementation of 1000 IU of vitamin D3 daily leads to an approximate increase in $25(\mathrm{OH}) \mathrm{D}$ levels by $10-20 \mathrm{ng} / \mathrm{mL}(25-50 \mathrm{mmol} / \mathrm{L})$, [97-99]. Findings from randomised placebo-controlled trials conducted during the winter have shown that each $1 \mathrm{mg}$ of supplemental vitamin $\mathrm{D}$ is associated with an increase in serum $25(\mathrm{OH}) \mathrm{D}$ of between $0.7 \mathrm{nmol} / \mathrm{L}$ [100] and $2 \mathrm{nmol} / \mathrm{L}$ [75].

Several studies have observed the safety concerns regarding the dosage of vitamin D supplementation. However, oral vitamin D intakes of up to 10,000 IU daily were not associated with any harmful effects [101], since this dose is comparable to the maximum cutaneous vitamin 
D production, and reports of vitamin D intoxication from cutaneous synthesis alone do not exist [101]. In this context, the IOM and the European Food and Safety Authority (EFSA) recommend a safe tolerable upper intake level of 4000 IU vitamin D per day for all adults, including pregnant and lactating women [102], although, to date, very few studies have investigated the long-term effects of a vitamin $D$ intake above the suggested threshold of 4000 IU per day $[103,104]$. To reach a steady state, after two to three consecutive months of treatment with vitamin D supplementation, it's necessary a re-measurement of 25(OH)D serum levels [98].

Thus, the Nutritionists should consider a general vitamin D supplementation in populations at high risk for vitamin D deficiency, such as psoriatic patients [105]. The compounds of vitamin D commonly used in clinical trials varied from $1,25(\mathrm{OH}) \mathrm{D}$, the physiologically active form of vitamin $\mathrm{D}$, to $1 \alpha \mathrm{OHD}$, alfa-calcidol, requiring only liver metabolism to be converted to the active form to vitamin D or cholecalciferol, requiring both liver and kidney metabolism to become active. Perez et al. observed an overall $88 \%$ of clinical improvement of psoriasis with oral vitamin D with a decrease in mean PASI scores [61]. The results were confirmed in different studies on limited number of patients, reporting moderate or greater improvement in psoriasis in 25-50\% of subjects [106-109]. It has also been proposed the therapeutic use of systemic alphacalcidol in patients with psoriatic arthritis [61]. Another study demonstrated that a combination of acitretin and oral calcitriol resulted in a faster reduction of PASI in patients of chronic plaque psoriasis [110]. A study on a large population sample including 70,437 US females over a period of 14 years, examined the vitamin D intake levels and the incidence of psoriasis in the population. After adjusting for confounding variables, the study found that there was no significant association between vitamin D intake (dietary, supplementary, and total vitamin D) and the risk of incident psoriasis. Thus, the authors proposed that there was no role of dietary or supplemental vitamin D intake to prevent the development of psoriasis [111]. However, current recommendations for dietary intake of vitamin D are based only on its effect on skeletal health, while no information is present as regards psoriasis. In addition, a discrepancy between recommended RDAs and actual daily vitamin D intake exists. Therefore, solutions like food fortification and personalized diet or vitamin D supplementation in psoriatic patients need to be developed. In addition, taking into account the common association among psoriasis, obesity and Mets of which will be discussed in the next chapter, the advantage of the potential use of oral vitamin D supplementations to treat psoriasis and metabolic syndrome concurrently through its anti-inflammatory effects was strongly supported by a comprehensive meta-analysis including the results of clinical trials using vitamin $\mathrm{D}$ supplementation in psoriasis [106].

\subsection{Vitamin D, obesity and psoriasis}

Many studies showed the link between psoriasis, obesity and MetS [112, 113]. Obesity is an important risk factor for psoriasis $[114,115]$. The relationship between the two conditions is probably bidirectional, with obesity, mainly visceral obesity, predisposing to psoriasis and psoriasis favouring obesity [116]. In particular, there was a 2-fold increased risk for psoriasis development in the setting of obesity as compared with normal weight subjects [117]. In addition, for each unit increment increase in body mass index (BMI) was reported a 9\% higher risk for psoriasis onset and a $7 \%$ higher risk for increased of PASI score [118]. A further evidence of the link between, obesity, inflammation and cardiovascular diseases in patients with psoriasis is provided by several studies reporting a correlation between PASI score and increased of CRP levels [119] and between psoriasis and waist circumference [120]. CRP is an acute phase protein significantly associated with obesity, representing the most sensitive markers of inflammation and an independent risk for cardiovascular disease. Waist circumference represents a surrogate measure of fat distribution highly correlated with visceral fat [121], the main source of inflammatory cytokines in obesity [122]. In particular, obesity and psoriasis are both pro-inflammatory conditions, in which the adipokines balance is shifted in favor to action pro-inflammatory adipokines [123, 124]. On the one hand, the dominance of pro-inflammatory adipokines favors either the development and the maintenance of obesity and its consequences, including cardiovascular diseases, type 2 diabetes, and MetS [125]; on the other hand, the production of inflammatory cytokines in visceral obesity represents the link involved in the complex mechanisms leading to the exacerbation of psoriasis and to psoriasis co-morbidities [126]. Indeed, psoriasis is frequently associated with cardio-metabolic co-morbidities and with an increased cardiovascular mortality [127, 128].

Similarly, there are significant associations between low vitamin D status and increased risk of obesity and obesityrelated co-morbidities and cardiovascular mortality [127]. In particular, higher BMI leads to lower vitamin D status, with an inverse association between mortality risk and vitamin D levels, although this association could be indirectly mediated by the obesity per se [129]. Ju SY et al. performed a meta-analysis of the dose-response relationship between blood vitamin D levels and the risk of MetS. Using data on blood 25(OH)D levels, a monotonically decreasing relationship was observed for low levels of blood 25(OH)D in the pooled analyses of 16 cross-sectional studies $(\mathrm{OR}=0.89$ for $30 \mathrm{nmol} / \mathrm{L}, \mathrm{OR}=0.80$ for $60 \mathrm{nmol} / \mathrm{L}, \mathrm{OR}=0.71$ for $90 \mathrm{nmol} / \mathrm{L}$, and $\mathrm{OR}=0.63$ for $120 \mathrm{nmol} / \mathrm{L}$ ). A $25 \mathrm{nmol} / \mathrm{L}$ increase in $25(\mathrm{OH}) \mathrm{D}$ levels was associated with a $13 \%$ 
decrease in the risk of MetS in cross-sectional studies [130]. Several mechanisms might account for the low vitamin D status in obese subjects, [131]. Besides a low dietary intake of vitamin D linked to restrictive weight-loss diet regimen, the most likely explanations for low vitamin D status in obesity are sequestration of vitamin $\mathrm{D}$ in the adipose tissue [132], volumetric dilution related to the greater volume of distribution of $25(\mathrm{OH}) \mathrm{D}$, less exposure of skin to sunlight due to less outdoor activity and air pollution [133]. The associations of low vitamin D status with obesity on the one hand, and with psoriasis on the other hand, lend support to the hypothesis for considering vitamin $\mathrm{D}$ as a further link between obesity and psoriasis. In this contest, a vicious cycle could operate among low vitamin D status, obesity, and psoriasis, with additive detrimental effects on cardiometabolic risk in obese psoriatic patients. According to this hypothesis, vitamin D supplementation might be of particular usefulness for the prevention of psoriasis-related comorbidities.

\section{Conclusions}

Due to its role in proliferation and maturation of keratinocytes, vitamin $\mathrm{D}$ has become an important local therapeutic option in the treatment of psoriasis. Indeed, significant associations between low vitamin D status and psoriasis have been systematically observed. Although the exact role of vitamin D in the pathogenesis of psoriasis is unclear, understanding the possible bi-directional relationships between low vitamin D status and psoriasis is also important for delineating the risk profile for co-morbidities that may result from psoriasis, such as obesity, type 2 diabetes, and MetS. To date, the successful treatment based on adequate dietary intake of vitamin D or oral vitamin D supplementation in psoriasis represent an unmet clinical need and the evidence of its beneficial effects remains still controversial. Nevertheless, the Nutritionists should consider a general vitamin D supplementation in populations at high risk for vitamin D deficiency, such as psoriatic patients. This information is important either for Dermatologists and Nutritionists to increase the knowledge on the potential usefulness of vitamin D in psoriasis with the aim to reduce not only its clinical severity, but also cardiac risk factors and psoriasis co-morbidities. Future well-designed dietary intervention trials with vitamin D supplementations on large population samples are needed to define the specific dose of vitamin D supplementations for psoriasis.

1,25(OH)D, 1,25-hydroxyvitamin D or calcitriol; $25 \mathrm{OHD}$, 25-hydroxyvitamin $\mathrm{D} ; B M I$, body mass index; $C R P, \mathrm{C}$ reactive protein; $I L$, interleukin; MetS, metabolic disease; $P A S I$, psoriasis area and severity index; $R D A s$, recommended dietary allowances; $T N F$, tumor necrosis factor; $V D R$, vitamin D receptor.
Acknowledgements We would like to acknowledge all the Collaborators of this review: Antonio Improta, Dr. Lidia Albanese and Dr. Vincenza Grazia Mele.

\section{Compliance with ethical standards}

Conflict of interest statement and funding sources The authors declare that they have no conflict of interest. There was no funding source for this work.

Open Access This article is distributed under the terms of the Creative Commons Attribution 4.0 International License (http:// creativecommons.org/licenses/by/4.0/), which permits unrestricted use, distribution, and reproduction in any medium, provided you give appropriate credit to the original author(s) and the source, provide a link to the Creative Commons license, and indicate if changes were made.

\section{References}

1. Napolitano M, Caso F, Scarpa R, Megna M, Patrì A, Balato N, Costa L. Psoriatic arthritis and psoriasis: differential diagnosis. Clin Rheumatol. 2016;35(8):1893-901.

2. Reich $\mathrm{K}$. The concept of psoriasis as a systemic inflammation: implications for disease management. J Eur Acad Dermatol Venereol. 2012;26(Suppl 2):3-11.

3. Napolitano M, Megna M, Monfrecola G. Insulin resistance and skin diseases. Sci World J. 2015;2015:479354.

4. Lønnberg AS, Skov L. Co-morbidity in psoriasis: mechanisms and implications for treatment. Expert Rev Clin Immunol. 2016;28:1-8.

5. Nestle FO, Kaplan DH, Barker J. Psoriasis. N Engl J Med. 2009;361(5):496-509.

6. Lebwohl M. Psoriasis. Lancet. 2003;361(9364):1197-204.

7. Holick MF. Vitamin D deficiency. N Engl J Med. 2007;357:266-81.

8. Kovács S, Wilkens MR, Liesegang A. Influence of UVB exposure on the vitamin $\mathrm{D}$ status and calcium homoeostasis of growing sheep and goats. J Anim Physiol Anim Nutr (Berl). 2015;99(Suppl S1):1-12.

9. Mattozzi C, Paolino G, Richetta AG, Calvieri S. Psoriasis, vitamin $\mathrm{D}$ and the importance of the cutaneous barrier's integrity: an update. J Dermatol. 2016;43(5):507-14.

10. Wadhwa B, Relhan V, Goel K, Kochhar AM, Garg VK. Vitamin D and skin diseases: a review. Indian J Dermatol Venereol Leprol. 2015;81(4):344-55.

11. Soleymani T, Hung T, Soung J. The role of vitamin D in psoriasis: a review. Int J Dermatol. 2015;54(4):383-92.

12. Lowes MA, Suárez-Fariñas M, Krueger JG. Immunology of psoriasis. Annu Rev Immunol. 2014;32:227-55.

13. Harari M, Shani J, Hristakieva E, Stanimirovic A, Seidl W, Burdo A. Clinical evaluation of a more rapid and sensitive psoriasis assessment severity score (PASS), and its comparison with the classic method of psoriasis area and severity index (PASI), before and after climatotherapy at the Dead-Sea. Int $\mathrm{J}$ Dermatol. 2000;39(12):913-8.

14. Reichrath J. Vitamin D and the skin: An ancient friend, revisited. Exp Dermatol. 2007;16(7):618-25.

15. Bikle DD. Protective actions of vitamin D in UVB induced skin cancer. Photochem Photobiol Sci. 2012;11(12):1808-16.

16. Matsumoto K, Hashimoto K, Nishida Y, Hashiro M, Yoshikawa K. Growth-inhibitory effects of 1,25-dihydroxyvitamin D3 on 
normal human keratinocytes cultured in serum-free medium. Biochem Biophys Res Commun. 1990;166(2):916-23.

17. Gniadecki R. Stimulation versus inhibition of keratinocyte growth by 1,25-dihydroxyvitamin D3: dependence on cell culture conditions. J Invest Dermatol. 1996;106(3):510-6.

18. Datta Mitra A, Raychaudhuri SP, Abria CJ, Mitra A, Wright R, Ray R, Kundu-Raychaudhuri S. 1 $\alpha, 25$-dihydroxyvitamin-D3-3bromoacetate regulates $\mathrm{AKT} / \mathrm{mTOR}$ signaling cascades: a therapeutic agent for psoriasis. J Invest Dermatol. 2013;133(6):155664.

19. Hegyi Z, Zwicker S, Bureik D, Peric M, Koglin S, Batycka-Baran A, Prinz JC, Ruzicka T, Schauber J, Wolf R. Vitamin D analog calcipotriol suppresses the Th17 cytokine-induced proinflammatory S100 "alarmins" psoriasin (S100A7) and koebnerisin (S100A15) in psoriasis. J Invest Dermatol. 2012;132(5):1416-24.

20. Tu CL, Oda Y, Komuves L, Bikle DD. The role of the calciumsensing receptor in epidermal differentiation. Cell Calcium. 2004;35:265-73.

21. Xie Z, Bikle DD. Cloning of the human phospholipase C-gamma1 promoter and identification of a DR6-type vitamin D-responsive element. J Biol Chem. 1997;272:6573-7.

22. Bikle DD. Vitamin D regulated keratinocyte differentiation. J Cell Biochem. 2004;92:436-44.

23. Xie Z, Komuves L, Yu QC, Elalieh H, Ng DC, Leary C, Chang S, Crumrine D, Yoshizawa T, Kato S, Bikle DD. Lack of the vitamin $\mathrm{D}$ receptor is associated with reduced epidermal differentiation and hair follicle growth. J Invest Dermatol. 2002;118:11-6.

24. Okasaki T, Bell RM, Hannun YA. Sphingomyelin turnover induced by vitamin D3 in HL-60 cells. Role in cell differentiation. J Biol Chem. 1989;264:19076-80.

25. Lehmann B, Querings K, Reichrath J. Vitamin D and skin: new aspects for dermatology. Exp Dermatol. 2004;13(Suppl 4):11-5.

26. Luan $\mathrm{C}$, Chen $\mathrm{X}, \mathrm{Hu} \mathrm{Y}$, Hao Z, Osland JM, Chen X, Gerber SD, Chen M, Gu H, Yuan R. Overexpression and potential roles of NRIP1 in psoriasis. Oncotarget. 2016; doi:10.18632/oncotarget.12371.

27. Buckner JH. Mechanisms of impaired regulation by CD4(+) CD25(+) FOXP3(+) regulatory $\mathrm{T}$ cells in human autoimmune diseases. Nat Rev Immunol. 2010;10:849-59.

28. Sloka S, Silva C, Wang J, Yong VW. Predominance of Th2 polarization by vitamin D through a STAT6-dependent mechanism. J Neuroinflammation. 2011;8:56.

29. Van Etten E, Decallone B, Verlinden L, Verstuyf A, Bouillon R, Mathieu C, et al. Analogs of 1 $\alpha, 25$-dihydroxy vitamin D3 as pluripotent immunomodulators. J Cell Biochem. 2003;88:223-6.

30. Heilborn JD, Weber G, Gronberg A, Dieterich C, Stahle M. Topical treatment with the vitamin D analogue calcipotriol enhances the upregulation of the antimicrobial protein hCAP18/ LL-37 during wounding in human skin in vivo. Exp Dermatol. 2010;19:332-8.

31. Richetta AG, Silvestri V, Giancristoforo S, Rizzolo P, D'Epiro S, Graziano V, Mattozzi C, Navazio AS, Campoli M, D'Amico C, Scarnò M, Calvieri S, Ottini L. A-1012G promoter polymorphism of vitamin $\mathrm{D}$ receptor gene is associated with psoriasis risk and lower allele-specific expression. DNA Cell Biol. 2014;33(2):102-9.

32. Visconti B, Paolino G, Carotti S, Pendolino AL, Morini S, Richetta AG, Calvieri S. Immunohistochemical expression of VDR is associated with reduced integrity of tight junction complex in psoriatic skin. J Eur Acad Dermatol Venereol. 2015;29: 2038-42.

33. Kirschner N, Rosenthal R, Günzel D, Moll I, Brandner JM. Tight junctions and differentiation - a chicken or the egg question? Exp Dermatol. 2012;21:171-5.
34. Gisondi P, Rossini M, Di Cesare A, Idolazzi L, Farina S, Beltrami G. Vitamin D status in patients with chronic plaque psoriasis. Br J Dermatol. 2012;166:505-10.

35. Orgaz-Molina J, Buendía-Eisman A, Arrabal-Polo MA, Ruiz JC, Arias-Santiago S. Deficiency of serum concentration of 25hydroxyvitamin D in psoriatic patients: a case-control study. J Am Acad Dermatol. 2012;67:931-8.

36. El-Moaty Zaher HA, El-Komy MH, Hegazy RA, Mohamed El Khashab HA, Ahmed HH. Assessment of interleukin-17 and vitamin D serum levels in psoriatic patients. J Am Acad Dermatol. 2013;69:840-2.

37. Mehmood ZH, Papandreou D. An updated mini review of vitamin D and obesity: Adipogenesis and inflammation state. Open Access Maced J Med Sci. 2016;4(3):526-32.

38. de Gonçalves Carvalho CM, Ribeiro SM. Aging, low-grade systemic inflammation and vitamin D: a mini-review. Eur J Clin Nutr. 2016; doi:10.1038/ejen.2016.177.

39. Zhang Y, Leung DY, Richers BN, Liu Y, Remigio LK, Riches DW, Goleva E. Vitamin D inhibits monocyte/macrophage proinflammatory cytokine production by targeting MAPK phosphatase-1. J Immunol. 2012;188(5):2127-35.

40. Giulietti A, van Etten E, Overbergh L, Stoffels K, Bouillon R, Mathieu C. Monocytes from type 2 diabetic patients have a proinflammatory profile. 1,25-dihydroxyvitamin $\mathrm{D}(3)$ works as antiinflammatory. Diabetes Res Clin Pract. 2007;77(1):47-57.

41. Neve A, Corrado A, Cantatore FP. Immunomodulatory effects of vitamin $\mathrm{D}$ in peripheral blood monocyte-derived macrophages from patients with rheumatoid arthritis. Clin Exp Med. 2014;14(3):275-83.

42. Pilz S, Kienreich K, Rutters F, de Jongh R, van Ballegooijen AJ, Grübler M, Tomaschitz A, Dekker JM. Role of vitamin D in the development of insulin resistance and type 2 diabetes. Curr Diab Rep. 2013;13(2):261-70.

43. Calton EK, Keane KN, Newsholme P, Soares MJ. The impact of vitamin D levels on inflammatory status: a systematic review of immune cell studies. PLoS One. 2015;10(11):e0141770.

44. Yang M, Yang BO, Gan H, et al. Anti-inflammatory effect of 1, 25dihydroxyvitamin D (3) is associated with crosstalk between signal transducer and activator of transcription 5 and the vitamin D receptor in human monocytes. Exp Ther Med. 2015;9:1739-44.

45. Zuchi MF, Azevedo Pde O, Tanaka AA, Schmitt JV, Martins LE. Serum levels of 25-hydroxy vitamin D in psoriatic patients. An Bras Dermatol. 2015;90(3):430-2.

46. Kincse G, Bhattoa PH, Herédi E, Varga J, Szegedi A, Kéri J, Gaál J. Vitamin D3 levels and bone mineral density in patients with psoriasis and/or psoriatic arthritis. J Dermatol. 2015;42(7):679-84.

47. Grazio S, Naglić ĐB, Anić B, Grubišić F, Bobek D, Bakula M, Kavanagh HS, Kuna AT, Cvijetić S. Vitamin D serum level, disease activity and functional ability in different rheumatic patients. Am J Med Sci. 2015;349(1):46-9.

48. Miyachi Y, Ohkawara A, Ohkido M, Harada S, Tamaki K, Nakagawa H, Hori Y, Nishiyama S. Long-term safety and efficacy of high-concentration (20 microg/g) tacalcitol ointment in psoriasis vulgaris. Eur J Dermatol. 2002;12(5):463-8.

49. Kircik L. Efficacy and safety of topical calcitriol 3 microg/g ointment, a new topical therapy for chronic plaque psoriasis. J Drugs Dermatol. 2009;8(8 Suppl):s9-16.

50. Oquendo M, Abramovits W, Morrell P. Topical vitamin D analogs available to treat psoriasis. Skinmed. 2012;10:356-60.

51. Mason A, Mason J, Cork M, Hancock H, Dooley G. Topical treatments for chronic plaque psoriasis: an abridged Cochrane systematic review. J Am Acad Dermatol. 2013;69:799-807.

52. Prieto-Pérez R, Cabaleiro T, Daudén E, Ochoa D, Román M, Abad-Santos F. Pharmacogenetics of topical and systemic treatment of psoriasis. Pharmacogenomics. 2013;14:1623-34. 
53. Ahn CS, Awadalla F, Huang KE, Yentzer B, Dabade TS, Feldman SR. Patterns of vitamin $d$ analog use for the treatment of psoriasis. J Drugs Dermatol. 2013;12:906-10.

54. Mostafa WZ, Hegazy RA. Vitamin D and the skin: focus on a complex relationship: a review. J Adv Res. 2015;6(6):793-804.

55. Tremezaygues L, Reichrath J. Vitamin D analogs in the treatment of psoriasis: where are we standing and where will we be going? Dermatoendocrinology. 2011;3:180-6.

56. Balato N, Patruno C, Napolitano M, Patrì A, Ayala F, Scarpa R. Managing moderate-to-severe psoriasis in the elderly. Drugs Aging. 2014;31(4):233-8.

57. Napolitano M, Megna M, Balato A, Ayala F, Lembo S, Villani A, Balato N. Systemic treatment of pediatric psoriasis: a review. Dermatol Ther (Heidelb). 2016;6(2):125-42.

58. Megna M, Napolitano M, Balato N, Monfrecola G, Villani A, Ayala F, Balato A. Efficacy and safety of ustekinumab in a group of 22 elderly patients with psoriasis over a 2-year period. Clin Exp Dermatol. 2016;41(5):564-6.

59. Van Der Kerkhof PC. Biological activity of vitamin D analogues in the skin, with special reference to antipsoriatic mechanisms. $\mathrm{Br}$ J Dermatol. 1995;132:675-82.

60. Peric M, Koglin S, Dombrowski Y, Gross K, Bradac E, Büchau A, et al. Vitamin D analog differentially control antimicrobial peptide/"alarmin" expression in psoriasis. PLoS One. 2009;4:e6340.

61. Perez A, Raab R, Chen TC, Turner A, Holick MF. Safety and efficacy of oral calcitriol (1,25 dihydroxyvitamin D) for the treatment of psoriasis. Br J Dermatol. 1996;134:1070-8.

62. Wolters M. Diet and psoriasis: experimental data and clinical evidence. Br J Dermatol. 2005;153(4):706-14.

63. Barrea L, Macchia PE, Tarantino G, Di Somma C, Pane E, Balato N, Napolitano M, Colao A, Savastano S. Nutrition: a key environmental dietary factor in clinical severity and cardio-metabolic risk in psoriatic male patients evaluated by 7-day food-frequency questionnaire. J Transl Med. 2015;13:303.

64. Barrea L, Balato N, Di Somma C, Macchia PE, Napolitano M, Savanelli MC, Esposito K, Colao A, Savastano S. Nutrition and psoriasis: is there any association between the severity of the disease and adherence to the Mediterranean diet? J Transl Med. 2015;13:18. doi:10.1186/s12967-014-0372-1.

65. Muscogiuri G, Orio F, Colao A. Letter to the editor: vitamin D: a wonder drug for the cure of type 2 diabetes? J Clin Endocrinol Metab. 2016;101(4):L43-4.

66. Qi D, Nie X, Cai J. The effect of vitamin D supplementation on hypertension in non-CKD populations: a systemic review and meta-analysis. Int J Cardiol. 2016;227:177-86.

67. Orgaz-Molina J, Magro-Checa C, Arrabal-Polo MA, RayaÁlvarez E, Naranjo R, Buendía-Eisman A, Arias-Santiago S. Association of 25-hydroxyvitamin D with metabolic syndrome in patients with psoriasis: a case-control study. Acta Derm Venereol. 2014;94(2):142-5.

68. Wise J. NICE advises certain groups to take daily vitamin D supplement. BMJ. 2014;348:g3349.

69. Cashman KD, Kiely M. EURRECA-estimating vitamin D requirements for deriving dietary reference values. Crit Rev Food Sci Nutr. 2013;53(10):1097-109.

70. Cashman KD, Kiely M. Recommended dietary intakes for vitamin D: where do they come from, what do they achieve and how can we meet them? J Hum Nutr Diet. 2014;27(5):434-42.

71. Ross AC, Manson JE, Abrams SA, Aloia JF, Brannon PM, Clinton SK, Durazo-Arvizu RA, Gallagher JC, Gallo RL, Jones G, Kovacs CS, Mayne ST, Rosen CJ, Shapses SA. The 2011 report on dietary reference intakes for calcium and vitamin $\mathrm{D}$ from the Institute of Medicine: what clinicians need to know. J Clin Endocrinol Metab. 2011;96(1):53-8.

72. Holick MF, Binkley NC, Bischoff-Ferrari HA, Gordon CM, Hanley DA, Heaney RP, Murad MH, Weaver CM. Evaluation, treatment, and prevention of vitamin D deficiency: an Endocrine Society clinical practice guideline. J Clin Endocrinol Metab. 2011;25:1911-30.

73. Dawson-Hughes B, Mithal A, Bonjour JP, Boonen S, Burckhardt P, Fuleihan GE, Josse RG, Lips P, Morales-Torres J, Yoshimura N. IOF position statement: vitamin $\mathrm{D}$ recommendations for older adults. Osteoporos Int. 2010;21(7):1151-4.

74. Lamberg-Allardt C, Brustad M, Meyer HE, Steingrimsdottir L. Vitamin D - a systematic literature review for the 5th edition of the Nordic nutrition recommendations. Food Nutr Res. 2013;57. doi:10.3402/fnr.v57i0.22671.

75. Cashman KD, Hill TR, Lucey AJ, Taylor N, Seamans KM, Muldowney S, Fitzgerald AP, Flynn A, Barnes MS, Horigan G, Bonham MP, Duffy EM, Strain JJ, Wallace JM, Kiely M. Estimation of the dietary requirement for vitamin D in healthy adults. Am J Clin Nutr. 2008;88(6):1535-42.

76. Lanham-New SA, Buttriss JL, Miles LM, Ashwell M, Berry JL, Boucher BJ, Cashman KD, Cooper C, Darling AL, Francis RM, Fraser WD, de Groot CP, Hyppönen E, Kiely M, Lamberg-Allardt C, Macdonald HM, Martineau AR, Masud T, Mavroeidi A, Nowson C, Prentice A, Stone EM, Reddy S, Vieth R, Williams $\mathrm{CM}$. Proceedings of the rank forum on vitamin $\mathrm{D}$. Br J Nutr. 2011;105(1):144-56.

77. Outila TA, Mattila PH, Piironen VI, Lamberg-Allardt CJ. Bioavailability of vitamin D from wild edible mushrooms (Cantharellus tubaeformis) as measured with a human bioassay. Am J Clin Nutr. 1999;69(1):95-8.

78. Calvo MS, Whiting SJ, Barton CN. Vitamin D fortification in the United States and Canada: current status and data needs. Am J Clin Nutr. 2004;80(6 Suppl):1710S-6S.

79. Ovesen L, Brot C, Jakobsen J. Food contents and biological activity of 25-hydroxyvitamin D: a vitamin D metabolite to be reckoned with? Ann Nutr Metab. 2003;47(3-4):107-13.

80. Schmid A, Walther B. Natural vitamin D content in animal products. Adv Nutr. 2013;4(4):453-62.

81. Mattila PH, Valkonen E, Valaja J. Effect of different vitamin D supplementations in poultry feed on vitamin D content of eggs and chicken meat. J Agric Food Chem. 2011;59(15):8298-303.

82. Kühn J, Schutkowski A, Hirche F, Baur AC, Mielenz N, Stangl GI. Non-linear increase of vitamin D content in eggs from chicks treated with increasing exposure times of ultraviolet light. J Steroid Biochem Mol Biol. 2015;148:7-13.

83. Liu J, Greenfield H, Strobel N, Fraser DR. The influence of latitude on the concentration of vitamin D3 and 25-hydroxy-vitamin D3 in Australian red meat. Food Chem. 2013;140(3):432-5.

84. Rejnmark L, Avenell A, Masud T, Anderson F, Meyer HE, Sanders KM, Salovaara K, Cooper C, Smith HE, Jacobs ET, Torgerson D, Jackson RD, Manson JE, Brixen K, Mosekilde L, Robbins JA, Francis RM, Abrahamsen B. Vitamin D with calcium reduces mortality: patient level pooled analysis of 70,528 patients from eight major vitamin D trials. J Clin Endocrinol Metab. 2012;97(8):2670-81.

85. Kiely M, Black LJ. Dietary strategies to maintain adequacy of circulating 25-hydroxyvitamin D concentrations. Scand J Clin Lab Invest Suppl. 2012;243:14-23.

86. Black LJ, Walton J, Flynn A, Cashman KD, Kiely M. Small increments in vitamin D intake by Irish adults over a decade show that strategic initiatives to fortify the food supply are needed. J Nutr. 2015;145(5):969-76.

87. Seamans KM, Cashman KD. Existing and potentially novel functional markers of vitamin D status: a systematic review. Am J Clin Nutr. 2009;89(6):1997S-2008S.

88. U.S. Department of Agriculture, Agricultural Research Service. 2011. USDA National Nutrient Database for standard reference, release 24. Nutrient Data Laboratory Home Page, http://www.ars.usda.gov/ba/bhnrc/ndl. 
89. van den Berg H. Bioavailability of vitamin D. Eur J Clin Nutr. 1997;51(Suppl 1):S76-9.

90. Grossmann RE, Tangpricha V. Evaluation of vehicle substances on vitamin D bioavailability: a systematic review. Mol Nutr Food Res. 2010;54(8):1055-61.

91. Wagner D, Sidhom G, Whiting SJ, Rousseau D, Vieth R. The bioavailability of vitamin $\mathrm{D}$ from fortified cheeses and supplements is equivalent in adults. J Nutr. 2008;138(7):1365-71.

92. Tangpricha V, Koutkia P, Rieke SM, Chen TC, Perez AA, Holick MF. Fortification of orange juice with vitamin D: a novel approach for enhancing vitamin D nutritional health. Am J Clin Nutr. 2003;77(6):1478-83.

93. Mattila P, Lehikoinen K, Kiiskinen T, Piironen V. Cholecalciferol and 25-hydroxycholecalciferol content of chicken egg yolk as affected by the cholecalciferol content of feed. J Agric Food Chem. 1999;47(10):4089-92.

94. Jakobsen J, Knuthsen P. Stability of vitamin D in foodstuffs during cooking. Food Chem. 2014;148:170-5.

95. Cashman KD. Vitamin D: Dietary requirements and food fortification as a means of helping achieve adequate vitamin D status. $\mathrm{J}$ Steroid Biochem Mol Biol. 2015;148:19-26.

96. Tripkovic L, Lambert H, Hart K, Smith CP, Bucca G, Penson S, Chope G, Hyppönen E, Berry J, Vieth R, Lanham-New S. Comparison of vitamin D2 and vitamin D3 supplementation in raising serum 25-hydroxyvitamin D status: a systematic review and meta-analysis. Am J Clin Nutr. 2012;95(6):1357-64.

97. Shab-Bidar S, Bours S, Geusens PP, Kessels AG, van den Bergh JP. Serum 25(OH)D response to vitamin D3 supplementation: a meta-regression analysis. Nutrition. 2014;30(9):975-85.

98. Autier P, Gandini S, Mullie P. A systematic review: influence of vitamin D supplementation on serum 25-hydroxyvitamin D concentration. J Clin Endocrinol Metab. 2012;97(8):2606-13.

99. Zittermann A, Ernst JB, Gummert JF, Börgermann J. Vitamin D supplementation, body weight and human serum 25hydroxyvitamin D response: a systematic review. Eur J Nutr. 2014;53(2):367-74.

100. Heaney RP, Davies KM, Chen TC, Holick MF, Barger-Lux MJ. Human serum 25-hydroxycholecalciferol response to extended oral dosing with cholecalciferol. Am J Clin Nutr. 2003;77(1): 204-10.

101. Zittermann A, Prokop S, Gummert JF, Börgermann J. Safety issues of vitamin D supplementation. Anti Cancer Agents Med Chem. 2013;13(1):4-10.

102. EFSA Panel on Dietetic Products, Nutrition and Allergies (NDA). Scientific opinion on the tolerable upper intake level of vitamin D. EFSA J. 2012;10:1-45.

103. Davidson MB, Duran P, Lee ML, Friedman TC. High-dose vitamin D supplementation in people with prediabetes and hypovitaminosis D. Diabetes Care. 2013;36(2):260-6.

104. Jorde R, Strand Hutchinson M, Kjærgaard M, Sneve M, Grimnes G. Supplementation with high doses of vitamin D to subjects without vitamin D deficiency may have negative effects: pooled data from four intervention trials in Tromsø. ISRN Endocrinol. 2013;2013:348705.

105. Brouwer-Brolsma EM, Bischoff-Ferrari HA, Bouillon R, Feskens EJ, Gallagher CJ, Hypponen E, Llewellyn DJ, Stoecklin E, Dierkes J, Kies AK, Kok FJ, Lamberg-Allardt C, Moser U, Pilz S, Saris WH, van Schoor NM, Weber P, Witkamp R, Zittermann A, de Groot LC. Vitamin D: Do we get enough? A discussion between vitamin $\mathrm{D}$ experts in order to make a step towards the harmonisation of dietary reference intakes for vitamin D across Europe. Osteoporos Int 2013;24(5):1567-1577.

106. Fu LW, Vender R. Systemic role for vitamin $d$ in the treatment of psoriasis and metabolic syndrome. Dermatol Res Pract. 2011;2011:276079.
107. Lakka HM, Laaksonen DE, Lakka TA, Niskanen LK, Kumpusalo E, Tuomilehto J, Salonen JT. The metabolic syndrome and total and cardiovascular disease mortality in middle-aged men. JAMA. 2002;288(21):2709-16.

108. Abramovits W. Calcitriol 3 microg/g ointment: an effective and safe addition to the armamentarium in topical psoriasis therapy. $\mathrm{J}$ Drugs Dermatol. 2009;8(8 Suppl):s17-22.

109. van de Kerkhof PC. The topical treatment of psoriasis. Clin Exp Dermatol. 2005;30(2):205-8.

110. Merola JF, Han J, Li T, Qureshi AA. No association between vitamin D intake and incident psoriasis among US women. Arch Dermatol Res. 2014;306(3):305-7.

111. Ezquerra GM, Regana MS, Millet PU. Combination of acitretin and oral calcitriol for treatment of plaque-type psoriasis. Acta Derma Venereol. 2007;87:449-50.

112. Azfar RS, Gelfand JM. Psoriasis and metabolic disease: epidemiology and pathophysiology. Curr Opin Rheumatol. 2008;20(4): 416-22.

113. Barrea L, Macchia PE, Di Somma C, Napolitano M, Balato A, Falco A, Savanelli MC, Balato N, Colao A, Savastano S. Bioelectrical phase angle and psoriasis: a novel association with psoriasis severity, quality of life and metabolic syndrome. J Transl Med. 2016;14(1):130.

114. Santos M, Fonseca HM, Jalkh AP, Gomes GP, Cavalcante AS. Obesity and dyslipidemia in patients with psoriasis treated at a dermatologic clinic in Manaus. An Bras Dermatol. 2013;88:913-6.

115. Barrea L, Nappi F, Di Somma C, Savanelli MC, Falco A, Balato A, Balato N, Savastano S. Environmental Risk Factors in Psoriasis: The Point of View of the Nutritionist. Int J Environ Res Public Health. 2016;13(5)

116. Carrascosa JM, Rocamora V, Fernandez-Torres RM, JimenezPuya R, Moreno JC, Coll-Puigserver N, et al. Obesity and psoriasis: inflammatory nature of obesity, relationship between psoriasis and obesity, and therapeutic implications. Actas Dermosifiliogr. 2014;105:31-44.

117. Debbaneh M, Millsop JW, Bhatia BK, Koo J, Liao W. Diet and psoriasis, part I: impact of weight loss interventions. J Am Acad Dermatol. 2014;71:133-40.

118. Wolk K, Mallbris L, Larsson P, Rosenblad A, Vingard E, Stahle M. Excessive body weight and smoking associates with a high risk of onset of plaque psoriasis. Acta Derm Venereol. 2009;89:492-7.

119. Beygi S, Lajevardi V, Abedini R. C-reactive protein in psoriasis: a review of the literature. J Eur Acad Dermatol Venereol: JEADV. 2014;28:700-11.

120. Tobin AM, Hackett CB, Rogers S, Collins P, Richards HL, O'Shea $\mathrm{D}$, et al. Body mass index, waist circumference and HOMA-IR correlate with the psoriasis area and severity index in patients with psoriasis receiving phototherapy. Br J Dermatol. 2014;171:436-8.

121. Bosy-Westphal A, Booke CA, Blocker T, Kossel E, Goele K, Later W, et al. Measurement site for waist circumference affects its accuracy as an index of visceral and abdominal subcutaneous fat in a Caucasian population. J Nutr. 2010;140:954-61.

122. Jensen MD. Role of body fat distribution and the metabolic complications of obesity. J Clin Endocrinol Metab. 2008;93:S57-63.

123. Toussirot E, Aubin F, Dumoulin G. Relationships between adipose tissue and psoriasis, with or without arthritis. Front Immunol. 2014;5:368.

124. Klöting N, Blüher M. Adipocyte dysfunction, inflammation and metabolic syndrome. Rev Endocr Metab Disord. 2014;15(4):277-87.

125. Prasad P, Kochhar A. Interplay of vitamin D and metabolic syndrome: a review. Diabetol Metab Syndr. 2016;10:105-12.

126. Wolk K, Sabat R. Adipokines in psoriasis: an important link between skin inflammation and metabolic alterations. Rev Endocr Metab Disord. 2016; doi:10.1007/s11154-016-9381-0. 
127. Devaraj S, Jialal G, Cook T, Siegel D, Jialal I. Low vitamin D levels in northern American adults with the metabolic syndrome. Horm Metab Res. 2011;43(1):72-4.

128. Baz-Hecht M, Goldfine AB. The impact of vitamin D deficiency on diabetes and cardiovascular risk. Curr Opin Endocrinol Diabetes Obes. 2010;17(2):113-9.

129. Earthman CP, Beckman LM, Masodkar K, Sibley SD. The link between obesity and low circulating 25-hydroxyvitamin D concentrations: considerations and implications. Int J Obes. 2012;36: 387-96.

130. Ju SY, Jeong HS, Kim DH. Blood vitamin D status and metabolic syndrome in the general adult population: a dose- response meta-analysis. J Clin Endocrinol Metab. 2014;99(3): 1053-63.

131. Vimaleswaran KS, Berry DJ, Lu C, Tikkanen E, Pilz S, Hiraki LT, Cooper JD, Dastani Z, Li R, et al. Causal relationship between obesity and vitamin D status: Bi-directional Mendelian randomization analysis of multiple cohorts. PLoS Med. 2013;10: e1001383.

132. Vanlint S. Vitamin D and Obesity. Nutrients. 2013;5:949-56.

133. Barrea L, Savastano S, Di Somma C, Savanelli MC, Nappi F, Albanese L, Orio F, Colao A. Low serum vitamin D-status, air pollution and obesity: a dangerous liaison. Rev Endocr Metab Disord. 2016; doi:10.1007/s11154-016-9388-6. 